\title{
COMPARISON OF PRODUCTION DISEASES OF COWS KEPT IN COLD- AND WARM LOOSE HOUSING SYSTEMS IN FINNISH DAIRY HERDS
}

\author{
Schnier, C. * \& Saloniemi, H. S. \\ *Dep. of Clinical Veterinary Sciences, PO-Box 57, University of Helsinki, Finland \\ email: christian.schnier@helsinki.fi
}

Finland's cold loose housing systems (CLH) for dairy cows have been compared to the more traditional warm loose housing systems (WLH) in regard to the incidences of udder and ovarial disorders, ketosis, parturient paresis and metritis. For both systems approximately 10,000 calvings on 210 farms during the years 1996 and 1997 were modelled using survival analysis and two-level logistic regression in an observational cohort study.

The results of the different multivariable models, the modelling process, model diagnostics and sample size and confidence limit analysis were combined in an attempt to estimate an unbiased risk ratio.

The estimated risk ratios show that there are some differences in the incidence of production diseases between the 2 farming systems. It could be seen from the diagnostics that they were influenced considerably by the modelling process and some 'influential farms'. Even though some disease incidences differed statistically significantly, the observed differences were small so that we concluded that they should not influence the farmers decision making about whether or not to build a CLH in Finland.

\section{ASSOCIATIONS BETWEEN DAIRY COW SOMATIC CELL COUNT AND FOUR TYPES OF BEDDING IN FREE STALLS}

\author{
Kirkegaard P, Agger JF, Bjerg B. \\ Department of Animal Science and Animal Health. The Royal Veterinary and Agricultural University, \\ Grønnegårdsvej 8, DK-1870 Frederiksberg C, Denmark.
}

The purpose was to test the hypothesis of no difference in associations between four types of bedding material in free stalls and the cow somatic cell count (SCC) in a study population of primiparous cows in 52 Danish dairy herds. The types of bedding were 1) sand (20-25 cm deep), 2) straw (20 cm deep), 3) channel mattresses (channel bags filled with rubber granulate and a permeable top shield), and 4) two-layer mattresses with foam rubber and a rubber top cover. These bedding types were chosen because they all provided the necessary cow comfort. The herds were randomly selected within each of the four types of bedding systems and represented all regions of Jutland in Denmark.

Information on the stable interior and hygiene, cow hygiene, feeding, health management, milking and ventilation were collected at farm visits. Data on milk production and somatic cell count were provided from The Danish Cattle Data Base. 
The results showed:

- increased SCC with increasing age of the farmer

- increased SCC with poorer hygiene in the milking barn.

- reduced SCC with increasing milk yield

- reduced SCC in cows fixed in standing position at the feeding table after milking.

- association between SCC and types of bedding

- interaction between type of bedding and fixing the cows after milking

- interaction between type of bedding and milk yield.

The final conclusion was that SCC was higher in straw bedded stalls than with channel matresses or two layer matresses. The last two were at the same level. Sand bedding was not statistically significant from the three other, but was between straw and mattresses.

Other conclusions:

- cows on straw or sand had intact skin and hair coat on the hocks

- cows on straw or sand were more clean

- increased amount of straw in straw beds and on mattresses improved cow hygiene

- many cows had hair loss and hyperceratosis on the neck in houses with a neck bar at the feeding table

- there was a large variation in the stall dimensions within the cow houses

\title{
THE IMPACT OF HOUSING AND MANAGEMENT ON HEALTH AND WELFARE OF DAIRY CATTLE
}

\author{
G. Regula, J. Danuser, B. Spycher and B. Wechsler \\ Swiss Federal Veterinary Office, 3003 Bern, Switzerland
}

The objective of this study was to identify the effect of different housing systems and exercise of cows on indicators of health and welfare. Three groups of farms were compared: (1) tie stalls with little exercise during winter, (2) tie stalls with regular exercise outdoors (paddock or pasture), (3) free stalls with regular access to an outdoor paddock.

Farms were recruited by sending a letter to farms randomly selected from a central data-base. 50\% of the farm managers volunteered to participate in the study. 45 farms from each housing system were randomly selected among volunteers. Each farm was visited 3 times during a 2-year period. Farm managers were interviewed on management practices, and the housing system was described. In the winter 1999 and the winter 2000, a veterinarian observed the behaviour of 5 cows during lying and standing up. In addition, a short clinical examination was performed on each dairy cow. The emphasis was on recording injuries around the joints and at the trunk, and on observing lameness in cows walking to pasture. Data on reproductive performance and medical records were also collected. 
Data were analysed by multiple regression analysis. The effects of housing system and exercise of cows were corrected for cofactors such as herd size, location of farm, type of building, and education of farm manager. Factors that were significant over both years are reported here.

In 1999 and 2000, the prevalence of cows with some restrictions of the space for lying was $41 \%$ and $51 \%$ respectively in tie stalls with minimal exercise. In free stalls, this prevalence was reduced by $19 \%$ and 29\% (absolute numbers). There was no significant influence of housing system or exercise on the behaviour during standing up. Free stalls had a $6 \%$ lower prevalence of lameness than tie stalls. In addition, regular exercise prevented lameness ( $1 \%$ less per additional day of exercise per week). Cows in stalls with a long lying area had, on average, a 10\% lower prevalence of lameness in 1999 and a 4\% lower prevalence in 2000 compared to cows in stalls with a short lying area. Injuries of the skin around the joints were $12 \%$ and $16 \%$ less frequent in free stalls than in tie stalls. For each additional day of exercise, $3 \%$ less injuries were observed. In farms that could not provide exercise to cows during poor weather conditions, injuries at the trunk were $1 \%$ more frequent when they let the cows outside one additional day. On the other hand, if cows could exercise regardless of the weather, $5 \%$ less injuries were recorded. Calluses at the carpal joints were $19 \%$ and $18 \%$ less prevalent in free stalls and in farms with the ability to let cows outside regardless of weather conditions. A large amount of straw or other bedding materials also reduced calluses at the carpal joints (16\% and $18 \%$ less in 1999 and 2000 respectively).

Although reproductive performance tended to be poorer in tie than in free stalls, these differences were not significant. Farms with tie stalls and little exercise of cows during winter needed, on average, 6.3 treatments per 10 cows and year, 5 of which were antibiotic treatments. Free stalls averaged 2 treatments less, 1 of which was an antibiotic.

This study showed that exercise is beneficial dairy cows. Especially free stalls with permanent access to an outdoor paddock had a positive effect on health and welfare.

\title{
ESTIMATING THE ECONOMIC LOSSES ASSOCIATED WITH BVD INFECTION IN THE UK DAIRY HERD
}

\author{
GJ Gunn, R W Humphry, GJ Jones \& AW Stott \\ Epidemiology Unit, Scottish Agricultural College Veterinary Science Division, Inverness, Scotland. IV2 4JZ. \\ Telephone - 0044(0)1463243030 \\ Facsimile - 0044 (0)1463 243030, e-mail - g.gunn@ed.sac.ac.uk
}

The objective of this Milk Development Council study was to provide a farm level overview of the economic losses associated with bovine viral diarrhoea (BVD) infection for UK dairy herds. This disease is possibly the most important endemic infectious disease of cattle in Europe. However there have been few farm level estimates of the losses associated with UK dairy herd infection although Gunn et al (1998) examined losses for Scottish beef herds. The research team used computer-modelling techniques to build simulation models of BVD outbreaks and contrast them with BVD free 
herds. This provides a simple way of pooling and interpreting the available knowledge. Here the results of a basic simulation exercise that provides the basis for economic appraisal under different management/market scenarios are reported.

The methodology uses a spreadsheet based Markov Chain Model (Agrawal, R. C. \& Heady, E. O., 1972) to integrate the epidemiology of bovine BVD virus infections within the farm animal management system. From each stochastic spreadsheet model a range of outputs was generated to allow the calculation of losses for UK dairy herds as average Net Present Values (NPV) over a 10-year period. Sensitivity analysis of the model showed that herd size appeared to influence the epidemiology of BVD, affected the profitability of the farm and hence on the proportion of income lost due to BVD. Farm. Milk price also influenced the scale of the loss and the death rate for persistently infected cattle (PIs) influenced the range in losses. For example a 50-cow herd with a $50 \%$ death rate pa for PIs and a milk price of $£ 0.18 / 1$ the median loss due to BVD over a ten-year period is estimated to be $£ 10,300$ (range $£ 5,200$ to $£ 21,200$ ). When the milk price increases to $£ 0.20 / 1$ then the median loss would be $£ 10,400$ (range $£ 4,300$ to $£ 21,500$ ). For that herd the proportion of potential income lost would be $19 \%$ (range $10 \%$ to $39 \%$ ) at a milk price of $£ 0.18 / 1$ but $9 \%$ (range $4 \%$ to $19 \%$ ) at a milk price of $£ 0.20 / 1$.

The least expensive outbreaks, on average, would be for small herds with a low milk price and a high death rate for PIs. However, over a 10 -year period this would represent $20 \%$ loss in income due to BVD. The most expensive outbreaks were for the largest herds when the milk price was high and the death rate among PIs was low. However, over a 10 -year period this loss would only represent $8 \%$ of those farm incomes. It appears that BVD might be potentially most damaging in small herds.

\section{References}

Agrawal, R. C. \& Heady, E. O. 1972 Markov Chain Processes. In Methods for Agricultural Decisions, pp. 179194: Iowa State University Press.

Gunn, G. J., Stott, A. W. \& Scanlan, S. A. 1998 Estimating the losses associated with bovine viral diarrhoea (BVD) within the Scottish cow-calf herd. In World Association for Buiatrics XX Congress, pp. 1015-1017. Sydney.

\section{Acknowledgements}

SERAD provide SAC with financial support. MDC funded the study. 